\title{
Energy requirements and aging
}

\author{
Susan B Roberts* and Gerard E Dallal \\ Jean Mayer USDA Human Nutrition Research Center on Aging, Tufts University, 711 Washington St., Boston, \\ MA 02111 , USA
}

\begin{abstract}
Objective: To summarise the literature on energy requirements and aging. Design: An analysis and review of published data on components of energy expenditure and total energy expenditure (TEE).

Setting: Data on basal metabolic rate (BMR) and TEE were obtained from the US Institute of Medicine of the National Academies database (all available data from studies published before 2001, collected from 20 researchers willing to provide individual subject results).

Subjects: Those individuals from the database who were 20-100 years of age.

Results: TEE and physical activity level (PAL, defined as the ratio of total to resting energy expenditure) declined progressively throughout adult life in both normal weight and overweight men and women. In normal weight individuals (defined as body mass index (BMI) $18.5-25.0 \mathrm{~kg} \mathrm{~m}^{-2}$ ) TEE fell by $\approx 150 \mathrm{kcal}$ per decade, and PAL fell from an average of 1.75 in the second decade of life to 1.28 in the ninth decade. Thermic effect of feeding data from other published studies indicated no consistent change associated with aging.

Conclusions: Aging is associated with progressive declines in resting and TEE, which have implications for defining dietary energy requirements at different stages of adult life.
\end{abstract}

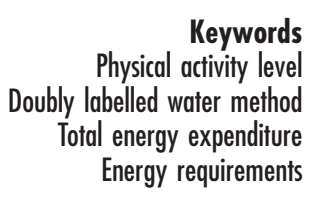

Keywords Physical activity level tal energy expenditure Energy requirements

\section{Previous use of the factorial method for determination of energy requirements}

\section{Background}

Previous recommendations on dietary energy needs ${ }^{1}$ were based on the 'factorial method' of estimating energy expenditure. The factorial method calculates for 24 hour total energy expenditure (TEE) using information on the time devoted to different activities and the energy costs of each activity, and assumes that TEE is equal to energy requirements in weight stable individuals. The advantage of the factorial method is that it allows for theoretical estimation of TEE for defined activity patterns, and thus, mean expected energy requirements for different levels of physical activity can be defined.

However, there are recognised theoretical problems with the factorial method that create uncertainty about the validity of its predictions of energy requirements. One problem is that it is not feasible to measure the energy costs of all activities performed during normal life. Thus, although generalisations about the energy costs of different daily activities are essential, they may introduce substantial error. Even activities that were once thought to be equivalent to basal metabolic rate (BMR), such as sleeping, have now been shown to have unique energy needs that require separate quantification ${ }^{2}$. A further concern is that the act of measuring the energy costs of specific activities may affect the outcome. For example, embarrassment or awareness may change effort level. In addition, the mechanical difficulties associated with performing an activity while wearing unfamiliar equipment may change the energy costs of some activities.

A further concern is that, by definition and design, the factorial method takes into account only those activities that can be specifically accounted for, such as sleeping, walking, household work and occupational activity. However, 24-hour room calorimeter studies have shown that a significant amount of energy is expended in 'nonaccountable' activities such as fidgeting, ranging from 100 to $800 \mathrm{kcal} \mathrm{day}^{-1}$ between individuals ${ }^{3}$. It has, therefore, been suggested that the factorial method may underestimate usual energy needs ${ }^{4,5}$, and most assessments of TEE using the doubly labelled water method have found significantly higher measured values for TEE than predicted energy requirements based on the factorial method $^{5-8}$. In the two direct comparisons of the factorial method with measured TEE, one found that the factorial method underestimated energy needs ${ }^{9}$ and one found no difference between the methods ${ }^{10}$. It should be noted that the latter study ${ }^{10}$ investigated an elderly 
population with a mean age of 70 years. Non-accountable activities such as fidgeting are likely to be reduced in such an elderly population, with the result that the factorial method and doubly labelled water derived estimates of energy requirements would be predicted to be more similar than in a young adult population.

Despite these limitations to the factorial method, other approaches available at the time the Food and Agricultural Organization/World Health Organization/United Nations University (FAO/WHO/UNU) 1985 report $^{1}$ was being developed were recognised to be even less satisfactory. For example, the reported energy intakes of weight-stable subjects (i.e. those in energy balance) can theoretically be used to predict energy requirements for weight maintenance. However, clinical studies show weight loss in subjects provided with a diet containing the amount of metabolisable energy that they reported eating ${ }^{11-13}$. In addition, the doubly labelled water method (see below) gives estimates for TEE in free-living subjects that are consistently higher than reported energy intakes in a wide range of subjects. There is also a particular concern that different population groups underreport energy intake to a different extent - for example, underreporting may be increased in those who are overweight or obese ${ }^{14}$. Different races (and perhaps nationalities) may also underreport to a different extent ${ }^{15}$, presumably because of different sensitivities to psychological issues relating to eating and body weight.

\section{The doubly labelled water method for assessment of TEE and energy requirements}

The doubly labelled water method is a newer technique for measuring TEE. During formulation of the 1985 recommendations on dietary energy needs ${ }^{1}$, it was still in the validation phase of its use in human subjects. Since then, it has become a widely used tool for determining TEE in free-living subjects. As described elsewhere ${ }^{16-18}$, the basis of the doubly labelled water method, as originally proposed and developed by Lifson for use in small animals ${ }^{19,20}$, is that two isotopes of water $\left(\mathrm{H}_{2}{ }^{18} \mathrm{O}\right.$ and ${ }^{2} \mathrm{H}_{2} \mathrm{O}$ ) are administered and their disappearance rates from a body fluid such as urine monitored for a period of time optimally equivalent to $1-3$ half-lives for isotope disappearance (7-21 days in most human subjects). The disappearance rate of ${ }^{2} \mathrm{H}_{2} \mathrm{O}$ reflects water flux, while that of $\mathrm{H}_{2}{ }^{18} \mathrm{O}$ reflects water flux plus carbon dioxide production rate (through the rapid equilibration of the body water and bicarbonate pools resulting from the carbonic anhydrase reaction) $)^{21}$. The difference between the two disappearance rates can, therefore, be used to quantify carbon dioxide production rate, from which TEE can be calculated.

To predict TEE from a measurement of carbon dioxide production, it is necessary to have an estimate of the respiratory quotient (RQ) of the subject during the measurement period. This is because the heat equivalent of carbon dioxide varies with the substrates being oxidised. Short-term measurements of RQ by indirect calorimetry are not appropriate for use with the doubly labelled water technique because RQ varies during the day in association with food consumption. An alternative and more accurate approach is to estimate RQ from information on the subjects' dietary intake - either their reported macronutrient intakes or normative data from population surveys. (Note: RQ is better known as FQ, or food quotient, when calculated from dietary data.) This approach assumes that the balance of macronutrients is reported accurately even when energy intake is not. Although this assumption may not be entirely correct $^{22}$, FQ varies relatively little with quite wide variations in dietary composition. Diets providing 20\% and 40\% of energy from fat, for example, have a difference of only 0.06 in their FQ. Thus, making assumptions that normative or individual dietary data provides an accurate estimate of FQ will introduce relatively little error into doubly labelled water determinations of TEE. The assumption that individuals consume a diet providing 30\% of energy from fat when true fat intake is $20 \%$ or $40 \%$ would translate into an error in energy expenditures of about only $3 \%$.

Several validations of the doubly labelled water method have been conducted in which doubly labelled waterderived estimates of TEE were compared with measurements of energy expenditure made in a whole-body calorimeter. Although validation studies conducted in whole-body calorimeters do not mimic normal life conditions, they do allow for an exact comparison of doubly labelled water with classic indirect calorimetry, which is considered to be a gold standard measurement of energy expenditure. As summarised elsewhere ${ }^{16,17}$ there was a close agreement between the mean carbon dioxide production rates determined by the two methods in the validation studies. The precision of doubly labelled water measurements, as assessed by the variability of individual doubly labelled water measurements from the indirect calorimetry assessments, was $2-5 \%$ in the different studies. These validation studies show that the doubly labelled water method can provide an accurate assessment of carbon dioxide production rate and hence TEE in a wide range of healthy human subjects.

One particular advantage of the doubly labelled water method is that it provides a long-term index of TEE. Because 1-3 half-lives of isotope disappearance are needed for isotopic abundances to be measured accurately by mass spectrometry ${ }^{23}$, optimal time periods for doubly labelled water measurements of TEE range from 1 to 3 weeks in most groups of human subjects. Thus, in contrast to other techniques such as the factorial method, doubly labelled water can provide energy expenditure estimations over biologically meaningful periods of time that can reduce imprecision through increased study duration. Moreover, because doubly 
labelled water is non-invasive (requiring only that the subject drink the stable isotopes and provide $3+$ urine specimens over the study period), usual activity is not affected and measurements can be made in subjects leading their usual daily lives.

One potential criticism of using available doubly labelled water data is that most of the studies did not use randomly selected individuals, and thus the data may not be representative of typical population groups. For this reason, it should be recognised that the collated doubly labelled water data are not necessarily a perfect dataset from which to derive energy requirements. In relation to this concern, it should be noted that the recent study of TEE by Bratteby et $a l .{ }^{24}$ measured TEE in a representative population sample, and values are consistent with other doubly labelled water data generated from similar groups. Thus, there is currently no evidence suggesting that the doubly labelled water database is not suitable as a basis for extrapolating to dietary energy recommendations, and the very limited available data on representative populations suggests that it is adequate.

A second potential criticism of using doubly labelled water determinations of TEE as a basis for dietary energy requirements is that it is necessary to assume that TEE is relatively unaffected by fluctuations in energy balance - in other words, increased or decreased energy intake by the subjects during TEE measurements did not cause equivalent changes in TEE (in which case the TEE measurements would reflect energy intake in an adapted state that might not be optimal for long-term good health). This assumption is incorrect in the sense that there is certainly some capacity for TEE to increase or decrease spontaneously when energy intake increases or decreases ${ }^{25-27}$. However, most overfeeding studies show that overeating is also accompanied by substantial weight gain, and likewise reduced energy intake induces weight $\operatorname{loss}^{28}$. Thus, although there is some adaptive capacity of TEE to adjust to changes in dietary energy availability, TEE at approximate weight maintenance appears to be a reasonable estimate of adult energy requirements for stable energy balance when weight is in a healthy range.

A third consideration about use of the National Academy of Sciences doubly labelled water database is that it contains no data from subjects in developing countries. There is currently no information on differences in TEE between individuals of different ages in developing countries, and further information on this topic is needed.

A critical mass of doubly labelled water data has now been accumulated on a wide range of age-groups and body sizes, and, therefore, it is possible to define human energy needs based on doubly labelled water estimates of TEE. A total of 802 data points from 122 studies in adults were obtained for analysis by the National Academy of Sciences, and this database is used here to summarise changes in energy expenditure with aging. The analyses presented here do not include data from published doubly labelled water studies that investigated specific disease states and there are no data from developing countries. In addition to TEE data, we discuss information on changes in BMR and thermic effect of food (TEF) with age.

\section{Changes in BMR with age}

BMR is one of the largest components of TEE, comprising $50-70 \%$ in most adults. Changes in BMR, therefore, have an important impact on TEE. A decline in BMR with adult aging in both men and women has been recognised for decades ${ }^{29}$ and is implicit in the Schofield equations for predicting $\mathrm{BMR}^{30}$ which were adopted with minor modification for use in the original $\mathrm{FAO} /$ WHO/UNU predictions of dietary energy needs ${ }^{1}$. BMR has previously been estimated to decline $1-2 \%$ per decade based on longitudinal BMR measurements ${ }^{29}$, and presumably this decline is due in part to the usual loss of fat free mass and gain of less metabolically active fat associated with aging. Most $\mathrm{t}^{31-37}$ though not all ${ }^{38,39}$ studies additionally suggest that BMR adjusted for the change in fat free mass (FFM) is $5 \%$ lower in older adults compared to young ones. The reason for this difference between young and older adults is not known, but may be due to an age-associated disproportionate loss of extremely metabolically active organ tissue and/or a decrease in metabolic rate per unit of specific lean tissues. Recent work has suggested that the decline in BMR with age may not be linear, with a breakpoint for more rapid decline apparently occurring around 40 years in men and 50 years in women ${ }^{38,40}$. In the case of women, this may be due to an accelerated loss of FFM during menopause ${ }^{41}$.

It should be noted that the secular increases in body weight currently occurring in many countries worldwide ${ }^{42}$ may impact on changes in BMR with age. For example, individuals who gain substantial amounts of weight as they get older could theoretically experience no decrease in BMR with age or even an increase in BMR with age, associated with gains of FFM and fat mass. The extent to which BMR may increase or decrease with age will presumably depend on the balance between weight gain tending to increase BMR and aging tending to decrease BMR per unit of FFM.

Figure 1 shows a plot of BMR in relation to age using the BMR data available in the National Academy of Sciences doubly labelled water database. Although this database is smaller than the ones used previously to develop the original FAO equations ${ }^{30}$ and the update of those equations by Henry ${ }^{43}$, it uses relatively more recent data which was presumably collected with more accurate instrumentation. Between ages 20 and 96 years, the difference in BMR between individuals within the healthy weight range (BMI 

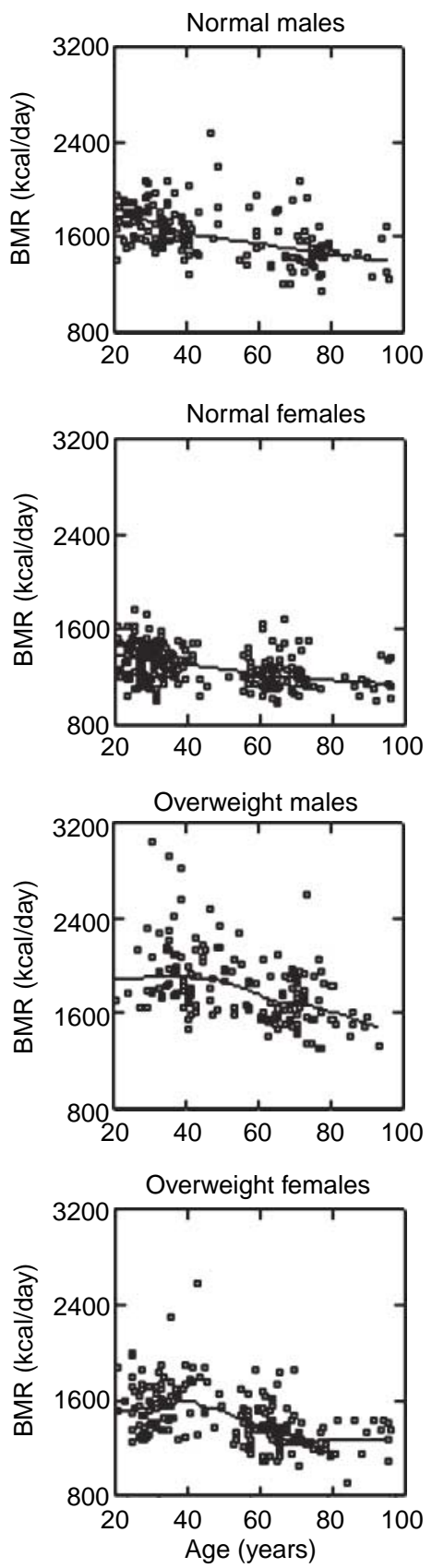

Fig. 1 Association between basal metabolic rate (BMR) and age in adult men and women within the normal weight range (body mass index (BMI), 18.5-25.0 kg m${ }^{-2}$ ) and the overweight/obese weight range (BMl, $>25.0 \mathrm{~kg} \mathrm{~m}^{-2}$ ). Data was obtained from the compilation of studies in the National Academy of Sciences database

18.5-25.0 $\mathrm{kg} \mathrm{m}^{-2}$ ) averaged a $2.0 \%$ decrease per decade in women and $2.9 \%$ in men. These values are perhaps somewhat higher than the $1-2 \%$ reported previously by Keys $^{29}$, and there was no obvious change in the rate of decline in BMR at any decade. In overweight men and women, who showed variations in weight by age (weight increased until 40-50 years), BMR was approximately constant until $40-50$ years and then decreased at a more rapid rate than in normal weight individuals, so that mean differences per decade of age were similar to those in normal weight individuals (1.9\% in women and 3.1\% in men). Further research is needed to examine age-related changes in BMR in individuals with different patterns of weight change, and to examine whether there are genderrelated differences in the change in BMR.

\section{Changes in the thermic effect of feeding with age}

TEF contributes $\approx 10 \%$ to TEE. Some studies report a decrease with aging ${ }^{44-50}$ while other studies report no change or a non-significant increase $\mathrm{e}^{34,37,51-54}$. Although no conclusive explanation can currently be given for the discrepant results, a suggested explanation ${ }^{53}$ is that TEF does not decline with aging per se, but that some studies may have confounded age with factors that decrease TEF independent of aging, such as obesity and/or digestive problems that limit nutrient absorption.

\section{Changes in TEE with age}

There is a recognised decrease in TEE with age ${ }^{55,56}$, and TEE is lower in elderly adults than young adults $8,16,33,57,58$. 24-hour sedentary energy expenditure measured in a whole body calorimeter with flexible activity requirements is also lower in elderly subjects compared to young ones ${ }^{36}$, but in whole body calorimeter protocols in which sedentary activity protocols are standardised 24 hour energy expenditure does not differ between young and old adults ${ }^{36,59}$. These data indicate declines in both intentional and spontaneous physical activity in old age in free-living individuals.

A summary of TEE and physical activity level (PAL) data from the National Academy of Sciences database is given in Figs. 2 and 3. In addition, Table 1 summarises data per decade of life. In normal weight men and women, in whom weight was relatively similar between individuals up to $\approx 60$ years of age and then decreased moderately after 60 years, TEE fell progressively from 20 years throughout the entire range of ages on whom data is available (up to 96 years). The decline for both men and women averaged $\approx 150 \mathrm{kcal}$ per decade between the second and ninth decades. PAL also decreased with increasing age, from an average of 1.75 for men and women in the second decade to 1.28 in the ninth decade (0.07 PAL units per decade). However, the question of whether PAL decreases linearly with age is not currently known. The cross-sectional PAL data shown in Fig. 3 suggests that PAL may be relatively constant between 20 and 40-50 years and then decreases rapidly. However, there are very few subjects in some decade groups, and thus the apparent findings are uncertain.

Figures 2 and 3 and Table 1 also show values for TEE and PAL in overweight men and women. Values for TEE are 
Table 1 A summary of collected TEE data: TEE and PAL by decade of adult age in normal weight and overweight men and women. Values are means \pm SD

\begin{tabular}{|c|c|c|c|c|c|c|}
\hline & $n$ & Weight & TEE & $\mathrm{PAL}^{\mathrm{a}}$ & $\mathrm{PAL}^{\mathrm{b}}$ & BMR \\
\hline \multicolumn{7}{|l|}{ Normal weight } \\
\hline \multicolumn{7}{|l|}{ Males } \\
\hline $20-29.9$ years & 48 & $70.7 \pm 6.0$ & $3047 \pm 510$ & $1.75 \pm 0.22$ & $1.73 \pm 0.27$ & $1770 \pm 155$ \\
\hline $30-39.0$ years & 47 & $71.7 \pm 6.8$ & $2964 \pm 429$ & $1.78 \pm 0.21$ & $1.75 \pm 0.24$ & $1676 \pm 151$ \\
\hline $40-49.9$ years & 22 & $70.6 \pm 6.7$ & $3048 \pm 419$ & $1.84 \pm 0.23$ & $1.81 \pm 0.23$ & $1683 \pm 269$ \\
\hline $50-59.9$ years & 8 & $73.1 \pm 10.8$ & $2513 \pm 401$ & $1.60 \pm 0.31$ & $1.47 \pm 0.27$ & $1590 \pm 211$ \\
\hline $60-69.9$ years & 14 & $67.8 \pm 6.1$ & $2397 \pm 437$ & $1.61 \pm 0.18$ & $1.72 \pm 0.24$ & $1487 \pm 227$ \\
\hline $70-79.9$ years & 30 & $70.0 \pm 6.7$ & $2407 \pm 374$ & $1.62 \pm 0.25$ & $1.71 \pm 0.25$ & $1497 \pm 183$ \\
\hline $80-89.9$ years & 4 & $67.1 \pm 4.0$ & $1700 \pm 239$ & $1.17 \pm 0.15$ & $1.24 \pm 0.20$ & $1457 \pm 21$ \\
\hline $90-96.5$ years & 6 & $65.6 \pm 7.3$ & $1935 \pm 156$ & $1.38 \pm 0.17$ & $1.43 \pm 0.10$ & $1415 \pm 184$ \\
\hline \multicolumn{7}{|l|}{ Females } \\
\hline $20-29.9$ years & 76 & $59.4 \pm 6.6$ & $2428 \pm 388$ & $1.79 \pm 0.28$ & $1.78 \pm 0.28$ & $1361 \pm 157$ \\
\hline $30-39.0$ years & 59 & $58.7 \pm 5.9$ & $2412 \pm 311$ & $1.83 \pm 0.26$ & $1.83 \pm 0.23$ & $1328 \pm 129$ \\
\hline $40-49.9$ years & 8 & $58.2 \pm 6.2$ & $2441 \pm 412$ & $1.89 \pm 0.30$ & $1.85 \pm 0.28$ & $1300 \pm 166$ \\
\hline $50-59.9$ years & 18 & $59.8 \pm 5.1$ & $2182 \pm 375$ & $1.75 \pm 0.22$ & $1.64 \pm 0.26$ & $1241 \pm 26$ \\
\hline $60-69.9$ years & 48 & $59.0 \pm 5.5$ & $2042 \pm 343$ & $1.69 \pm 0.31$ & $1.71 \pm 0.30$ & $1219 \pm 161$ \\
\hline $70-79.9$ years & 14 & $59.0 \pm 7.7$ & $1888 \pm 295$ & $1.55 \pm 0.26$ & $1.59 \pm 0.28$ & $1229 \pm 147$ \\
\hline $80-89.9$ years & 6 & $51.9 \pm 3.1$ & $1382 \pm 152$ & $1.21 \pm 0.09$ & $1.22 \pm 0.14$ & $1143 \pm 54$ \\
\hline $90-96.5$ years & 9 & $52.2 \pm 5.7$ & $1356 \pm 166$ & $1.17 \pm 0.13$ & $1.20 \pm 0.13$ & $1168 \pm 153$ \\
\hline \multicolumn{7}{|l|}{ Overweight } \\
\hline \multicolumn{7}{|l|}{ Males } \\
\hline $20-29.9$ years & 10 & $89.9 \pm 23.1$ & $3224 \pm 842$ & $1.90 \pm 0.20$ & $1.58 \pm 0.38$ & $1858 \pm 258$ \\
\hline $30-39.0$ years & 53 & $102.4 \pm 27.9$ & $2275 \pm 753$ & $1.81 \pm 0.30$ & $1.66 \pm 0.35$ & $2046 \pm 336$ \\
\hline $40-49.9$ years & 37 & $94.6 \pm 17.2$ & $3465 \pm 588$ & $1.88 \pm 0.24$ & $1.77 \pm 0.23$ & $1878 \pm 251$ \\
\hline $50-59.9$ years & 17 & $100.3 \pm 14.9$ & $3458 \pm 644$ & $1.88 \pm 0.29$ & $1.71 \pm 0.28$ & $1857 \pm 186$ \\
\hline $60-69.9$ years & 30 & $87.8 \pm 12.8$ & $2851 \pm 420$ & $1.71 \pm 0.29$ & $1.77 \pm 0.28$ & $1687 \pm 190$ \\
\hline $70-79.9$ years & 34 & $84.8 \pm 9.8$ & $2624 \pm 461$ & $1.55 \pm 0.27$ & $1.66 \pm 0.28$ & $1713 \pm 254$ \\
\hline $80-89.9$ years & 7 & $78.1 \pm 6.6$ & $2294 \pm 357$ & $1.47 \pm 0.16$ & $1.52 \pm 0.19$ & $1558 \pm 133$ \\
\hline $90-96.5$ years & 2 & $77.5 \pm 10.6$ & $1863 \pm 46$ & $1.29 \pm 0.13$ & $1.25 \pm 0.07$ & $1550 \pm 177$ \\
\hline \multicolumn{7}{|l|}{ Females } \\
\hline $20-29.9$ years & 33 & $83.4 \pm 17.0$ & $2713 \pm 394$ & $1.78 \pm 0.23$ & $1.58 \pm 0.18$ & $1536 \pm 214$ \\
\hline $30-39.0$ years & 41 & $83.9 \pm 13.7$ & $2794 \pm 358$ & $1.78 \pm 0.23$ & $1.83 \pm 0.21$ & $1587 \pm 201$ \\
\hline $40-49.9$ years & 14 & $96.9 \pm 26$ & $3032 \pm 545$ & $1.80 \pm 0.19$ & $1.86 \pm 0.22$ & $1696 \pm 311$ \\
\hline $50-59.9$ years & 29 & $83.3 \pm 17.5$ & $2349 \pm 368$ & $1.68 \pm 0.26$ & $1.55 \pm 0.23$ & $1409 \pm 167$ \\
\hline $60-69.9$ years & 46 & $78.2 \pm 13.4$ & $2061 \pm 294$ & $1.52 \pm 0.23$ & $1.51 \pm 0.21$ & $1374 \pm 190$ \\
\hline $70-79.9$ years & 19 & $69.3 \pm 7.9$ & $1868 \pm 402$ & $1.51 \pm 0.28$ & $1.45 \pm 0.29$ & $1234 \pm 89$ \\
\hline $80-89.9$ years & 6 & $62.8 \pm 5.6$ & $1748 \pm 464$ & $1.42 \pm 0.37$ & $1.41 \pm 0.33$ & $1233 \pm 205$ \\
\hline $90-96.5$ years & 7 & $74.8 \pm 7.3$ & $1766 \pm 292$ & $1.33 \pm 0.22$ & $1.32 \pm 0.23$ & $1332 \pm 125$ \\
\hline
\end{tabular}

TEE - total energy expenditure; PAL - physical activity level; BMR - basal metabolic rate.

a Using measured BMR values.

${ }^{\mathrm{b}}$ Using BMR predicted using the Schofield equations ${ }^{30}$.

consistently higher in overweight men and women than in normal weight men and women, but PAL values based on measured BMR show a decline with age similar to that of normal weight men and women. PAL values calculated using BMRs predicted from the Schofield equations ${ }^{30}$ were low for overweight men aged 20-39.9 years and overweight women aged 2029.9 years. This discrepancy highlights the need for improved equations for determination of BMR in overweight groups.

Using multiple regression analysis, there were significant gender and age effects on PAL, and a sex by weight interaction such that PAL was greater in overweight men than in normal weight men but lower in overweight women than in normal weight women. However, mean differences in PAL between groups were small (PAL for normal weight women, 1.73; for normal weight men, 1.70; for overweight women, 1.65 ; for overweight men, 1.74) and some decades of life had very few subjects. Thus, the extent to which available data was typical vs. atypical for different groups is not known and additional data is needed before changes in TEE and PAL with age and gender can be described accurately.

The decline in PAL with age in both men and women and normal weight and overweight are reported to parallel an increase in body fat mass ${ }^{60}$, though the extent to which the increase in body fat mass with age is a determinant or a cause of the age-related decrease in energy expenditure for physical activity is not known. Although some elderly individuals clearly are able to maintain very high levels of energy expenditure ${ }^{57}$ mean maximal oxygen consumption declines progressively with age in individuals with different occupations ${ }^{61}$. This suggests that at least some parallel changes in fitness, TEE and body composition with age are an inevitable consequence of the aging process, rather than a cumulative consequence of long- 

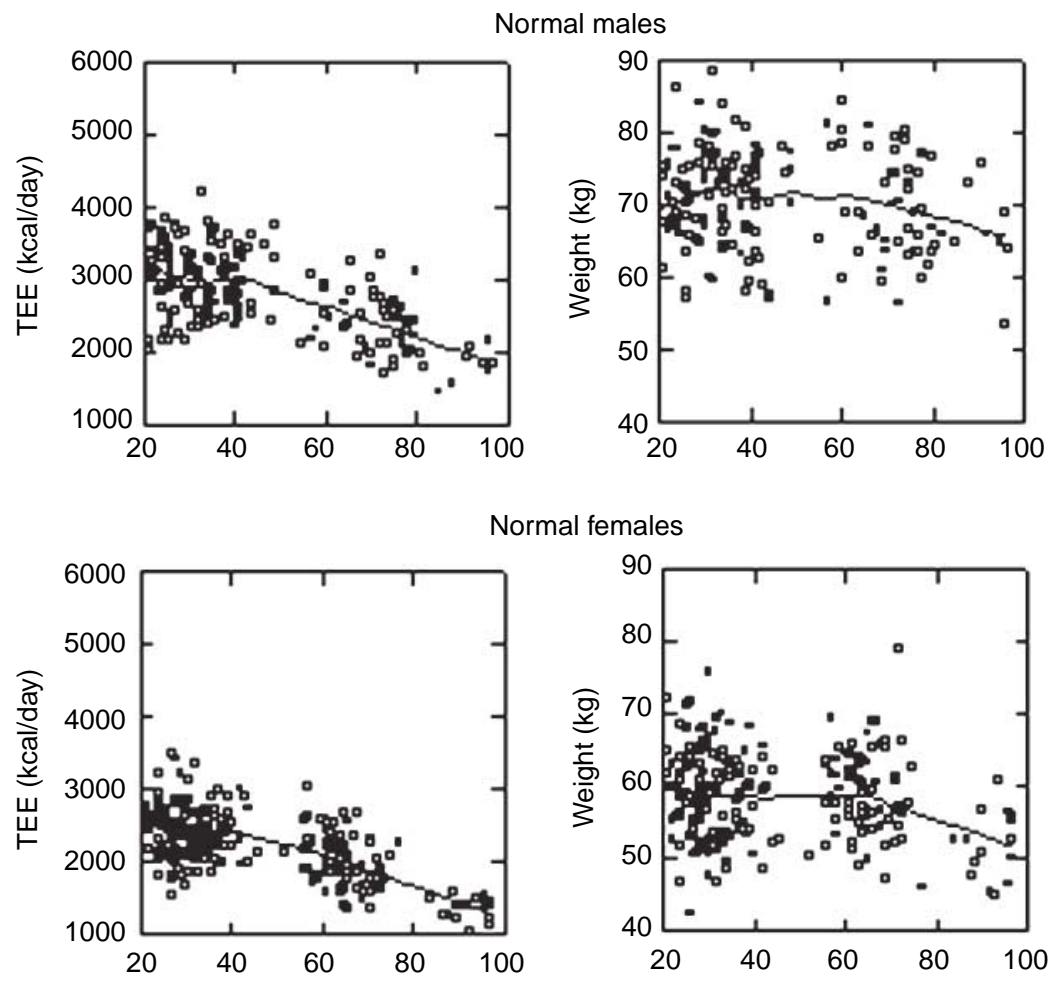

Overweight males
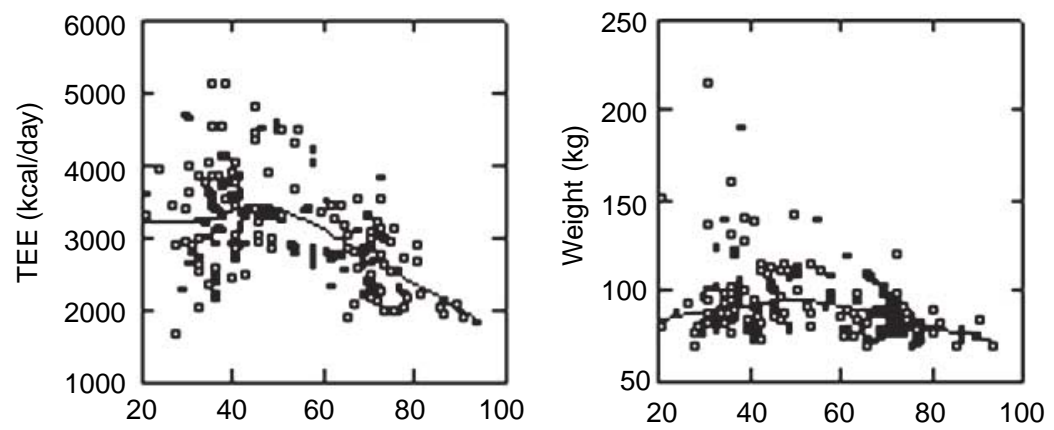

Overweight females
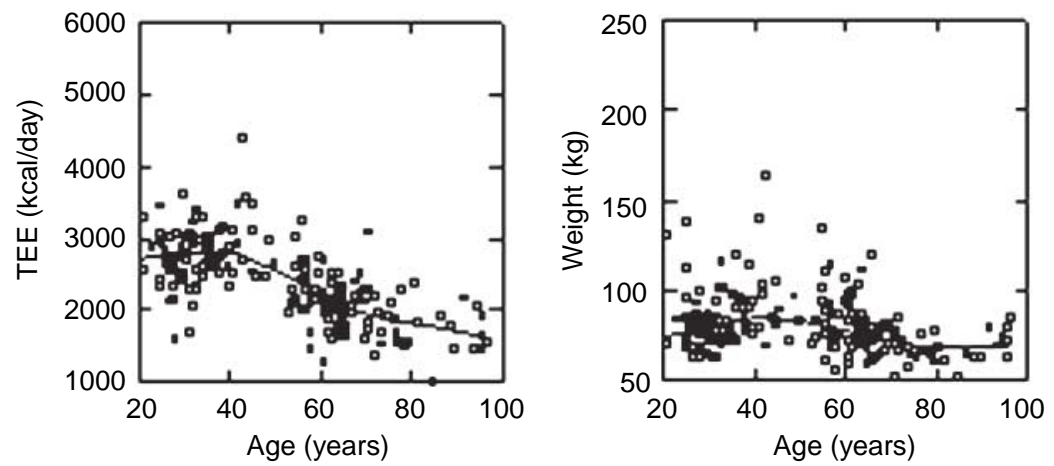

Fig. 2 Association between total energy expenditure (TEE) and age and body weight and age in adult men and women within the normal weight range (BMI, $18.5-25.0 \mathrm{~kg} \mathrm{~m}^{-2}$ ) and the overweight/obese weight range $\left(\mathrm{BMl}>25.0 \mathrm{~kg} \mathrm{~m}^{-2}\right.$ ). Data was obtained from the compilation of studies in the National Academy of Sciences database

term inactivity. Further studies are needed to determine the extent to which energy expenditure for physical activity can be maintained in old age in the general population.

\section{Summary}

Using available TEE data based on studies in developed countries, BMR, TEE and PAL decrease with age in both 

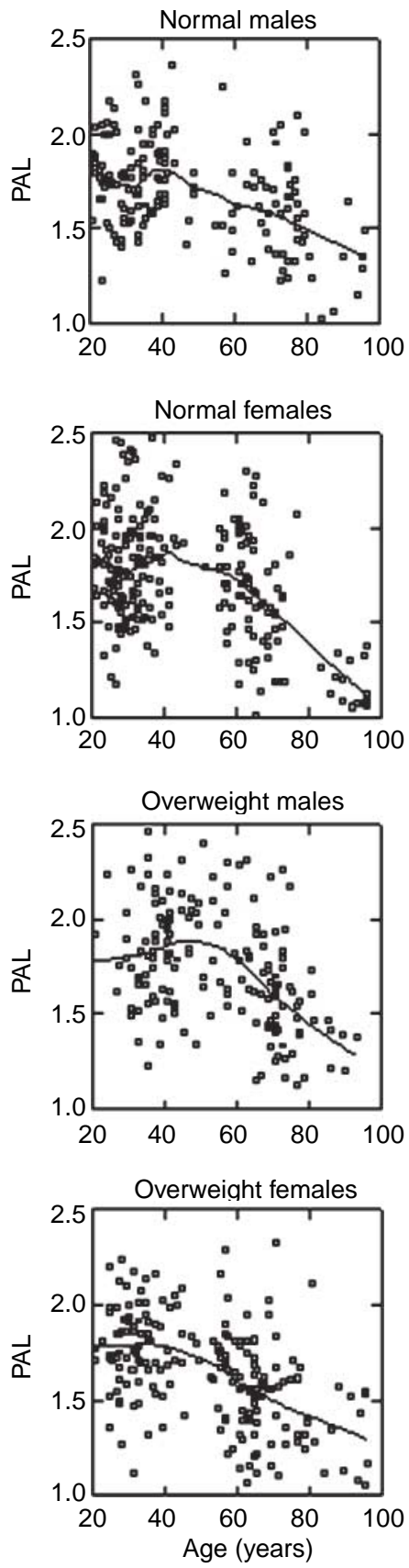

Fig. 3 Association between physical activity level (PAL, equal to total energy expenditure/basal metabolic rate) and age in adult men and women within the normal weight range (body mass index (BMI), $18.5-25.0 \mathrm{~kg} \mathrm{~m}^{-2}$ ) and the overweight/obese weight range $\left(\mathrm{BMI}>25.0 \mathrm{~kg} \mathrm{~m}^{-2}\right)$. Data was obtained from the compilation of studies in the National Academy of Sciences database

normal weight and overweight men and women. Mean PAL values average 1.75 for men and women aged 20-29.9 years, decrease to 1.65 at 60-69.9 years and 1.28 at 90-96.5 years. The values up to 60 years are higher than anticipated based on current estimates of energy needs ${ }^{1}$. There currently appear to be at most small effects of gender and overweight status on the relative change in
TEE and PAL with age, but this conclusion is tentative because the data are currently insufficient for many age-groups.

\section{References}

1 FAO, WHO, UNU. Energy and Protein Requirements. Report of a Joint FAO/WHO/UNU Expert Consultation. Technical Report Series 724. Geneva: World Health Organization, 1985.

2 Garby L. Metabolic adaptation to decreases in energy intake due to changes in the energy cost of low energy expenditure regimen. World Review of Nutrition and Dietetics 1990; 61 : $173-208$.

3 Ravussin E, Lillioja S, Anderson TE, Christin L, Bogardus C. Determinants of 24-hour energy expenditure in man, methods and results using a respiratory chamber. The Journal of Clinical Investigation 1986; 78: 1568-78.

4 Durnin JVGA. Low energy expenditures in free-living populations. European Journal of Clinical Nutrition 1990; 44: $95-102$.

5 Roberts SB, Heyman MB, Evans WJ, Fuss P, Tsay R, Young VR. Dietary energy requirements of young adult men, determined by using the doubly labelled water method. American Journal of Clinical Nutrition 1991; 54: 499-505.

6 Jones PJ, Martin LJ, Su W, Boyd NF. Canadian recommended nutrient intakes underestimate true energy requirements in middle-aged women. Canadian Journal of Public Health 1997; 88: 314-9.

7 Roberts SB. Energy expenditure and the development of early obesity. Annals of the New York Academy of Sciences 1993; 699: 18-25.

8 Sawaya AL, Saltzman E, Fuss P, Young VR, Roberts SB. Dietary energy requirements of young and older women determined by using the doubly labelled water method. American Journal of Clinical Nutrition 1995; 62: 338-44.

9 Leonard WR, Galloway VA, Ivakine E. Underestimation of daily energy expenditure with the factorial method: Implications for anthropological research. American Journal of Physical Anthropology 1997; 103: 443-54.

10 Morio B, Beaufrere B, Montaurier C, Verdier E, Ritz P, Fellmann N, Boirie Y, Vermorel M. Gender differences in energy expended during activities and in daily energy expenditure of elderly people. American Journal of Physiology Endocrinology and Metabolism 1997; 273: E321-7.

11 Mertz W, Tsui JT, Reiser S, Hallfrisch J, Morris ER, Steele PD, Lashley E. What are people really eating? The relation between energy intake derived from estimated diet records and intake determined to maintain body weight. American Journal of Clinical Nutrition 1991; 54: 291-5.

12 Pannemans DLE, Westerterp KR. Estimation of energy intake to feed subjects at energy balance as verified with doubly labelled water: a study in the elderly. European Journal of Clinical Nutrition 1993; 47: 490-6.

13 Seale JL. Energy expenditure measurements in relation to energy requirements. American Journal of Clinical Nutrition 1995; 62(S5): S1042-6.

14 Schoeller DA. How accurate is self-reported dietary energy intake? Nutrition Review 1990; 48: 373-9.

15 Tomoyasu NJ, Toth MJ, Poehlman ET. Misreporting of total energy intake in older African Americans. International Journal of Obesity and Related Metabolic Disorders: Journal of the International Association for the Study of Obesity 2000; 24(1): 20-6.

16 Roberts SB. Use of the doubly labelled water method for measurement of energy expenditure, total body water, water intake, and metabolizable energy intake in humans and 
small animals. Canadian Journal of Physiology and Pharmacology 1989; 67(10): 1190-8.

17 Schoeller DA. Measurement of energy expenditure in freeliving humans by using doubly labelled water. Journal of Nutrition 1988; 118: 1278-89.

18 Roberts SB. Use of the doubly labelled water method for measurement of energy expenditure, total body water, water intake, and metabolizable energy intake in humans and small animals. Canadian Journal of Physiology and Pharmacology 1989; 67: 1190-8.

19 Lifson N, Gordon GB, McClintock R. Measurement of total carbon dioxide production by means of $\mathrm{D}_{2}^{18} \mathrm{O}$. Journal of Applied Physiology 1955; 7: 704-10.

20 Lifson N. Theory of use of the turnover rates of body water for measuring energy and material balance. Journal of Theoretical Biology 1966; 12(1): 46-74.

21 Lifson N, Gordon GB, Visscher MB, Nier AO. The fate of utilized molecular oxygen and the source of oxygen of respiratory carbon dioxide, studied with the aid of heavy oxygen. The Journal of Biological Chemistry 1949; 180: 803-11.

22 Bathalon GP, Tucker KL, Hays NP, Vinken AG, Greenberg AS, McCrory MA, Roberts SB. Psychological measures of eating behavior and the accuracy of 3 common dietary assessment methods in healthy postmenopausal women. American Journal of Clinical Nutrition 2000; $\mathbf{7 1}$ : 739-45.

23 Schoeller DA. Energy expenditure from doubly labelled water: some fundamental considerations in humans. American Journal of Clinical Nutrition 1983; 38(6): 999-1005.

24 Bratteby LE, Sandhagen B, Lotborn M, Samuelson G. Daily energy expenditure and physical activity assessed by an activity diary in 374 randomly selected 15-year-old adolescents. European Journal of Clinical Nutrition 1997; 51(9): 592-600.

25 Bouchard C, Tremblay A, Despres J-P, Nadeau A, Lupien PJ, Theriault G, Dussault J, Moorjani S, Pinault S, Fournier G. The response to long-term overfeeding in identical twins. New England Journal of Medicine 1990; 322(21): 1477-82.

26 Levine JA, Eberhardt NL, Jensen MD. Role of nonexercise activity thermogenesis in resistance to fat gain in humans. Science 1999; 283: 212-4

27 Roberts SB, Young VR, Fuss P, Fiatarone MA, Richard B, Rasmussen H, Fiatarone M, Cortiella J, Dallal GE, Young VR. Energy expenditure and subsequent nutrient intakes in overfed young men. American Journal of Physiology 1990; 259: R461-9.

28 Saltzman E, Roberts SB. The role of energy expenditure in energy regulation: findings from a decade of research. Nutrition Review 1995; 53(8): 209-20.

29 Keys A, Taylor HL, Grande F. Basal metabolism and age of adult man. Metabolism 1973; 22: 579-87.

30 Schofield WN. Predicting basal metabolic rate, new standards and review of previous work. Human Nutrition: Clinical Nutrition 1985; 39(Suppl. 1): 5-41.

31 Fukagawa NK, Bandini LG, Young JB. Effect of age on body composition and resting metabolic rate. American Journal of Physiology 1990; 259: E233-8.

32 Klausen B, Toubro S, Astrup A. Age and sex effects on energy expenditure. American Journal of Clinical Nutrition 1997; 65: 895-907.

33 Pannemans DLE, Westerterp KR. Energy expenditure, physical activity and basal metabolic rate of elderly subjects. British Journal of Nutrition 1995; 73(4): 571-81.

34 Poehlman ET, Melby CL, Bradylak SF. Relation of age and physical exercise status on metabolic rate in younger and older healthy men. Journal of Gerontology 1991; 46(2): B54-8.
35 Roberts SB. Influence of age on energy requirements. American Journal of Clinical Nutrition 1995; 62(Suppl. 50A): $1053 \mathrm{~A}-8 \mathrm{~A}$

36 Vaughan L, Zurlo F, Ravussin E. Aging and energy expenditure. American Journal of Clinical Nutrition 1991; 53: $821-5$.

37 Visser M, Deurenberg P, van Staveren WA, Hautvast JGAJ. Resting metabolic rate and diet-induced thermogenesis in young and elderly subjects: relationship with body composition, fat distribution, and physical activity level. American Journal of Clinical Nutrition 1995; 61: $772-8$.

38 Poehlman ET, Goran MJ, Gardner AW, Ades PA, Arciero PJ, Katzman-Rooks SM, Montgomery SM, Toth MJ, Sutherland PT. Determinants of decline in resting metabolic rate in aging females. American Journal of Physiology Endocrinology and Metabolism 1993; 264: E450-5.

39 Tzankoff SP, Norris AH. Effect of muscle mass decrease on age-related BMR changes. Journal of Applied Physiology: Respiratory, Environmental and Exercise Physiology 1977; 43: 1001-6.

40 Poehlman ET. Energy expenditure and requirements in aging humans. Journal of Nutrition 1992; 122: 2057-65.

41 Haderslev KV, Svendsen OL, Staun M. Does paracentesis of ascites influence measurements of bone mineral or body composition by dual-energy X-ray absorptiometry? Metabolism 1999; 48(3): 373-7.

42 Popkin BM, Doak CM. The obesity epidemic is a worldwide phenomenon. Nutrition Review 1998; 56: 106-14.

43 Henry CJ. Mechanisms of changes in basal metabolism during ageing. European Journal of Clinical Nutrition 2000; 54(Suppl. 3): S77-S91.

44 Golay A, Schutz Y, Meyer HU. Glucose induced thermogenesis in nondiabetic and diabetic obese subjects. Diabetes 1982; 31: 1023-8.

45 Morgan JB, York DA. Thermic effect of feeding in relation to energy balance in elderly men. Annals of Nutrition and Metabolism 1983; 27: 71-7.

46 Schutz Y, Golay A, Felber J-P, Jequier E. Decreased glucoseinduced thermogenesis after weight loss in obese subjects: a predisposing factor for relapse obesity? American Journal of Clinical Nutrition 1984; 39: 380-7.

47 Schwartz RS, Jaegar LF, Veith RC. The thermic effect of feeding in older men: the importance of the sympathetic nervous system. Metabolism 1990; 39: 733-7.

48 Thorne A, Wahren J. Diminished meal-induced thermogenesis in elderly man. Clinical Physiology 1990; 10: 427-37.

49 Vansant G, VanGaal L, VanAcker K, DeLeeuw I. Importance of glucagon as a determinant of resting metabolic rate and glucose-induced thermogenesis in obese women. Metabolism 1991; 40(7): 672-5.

50 Golay A, Schutz Y, Meyer HU, Thiebaud D, Curchod B, Maeder E, Felber JP, Jequier E. Glucose-induced thermogenesis in nondiabetic and diabetic obese subjects. Diabetes 1982; 31: 1023-8.

51 Bloesch D, Schutz Y, Breitenstein E, Jequier E, Felber JP. Thermogenic response to an oral glucose load in man: comparison between young and elderly subjects. Journal of the American College of Nutrition 1988; 7(6): 471-83.

52 Fukagawa NR, Bandini LG, Lim PH, Roingeard F, Lee MA, Young JB. Protein-induced changes in energy expenditure in young and old individuals. The American Journal of Physiology 1991; 260(23): E345-52.

53 Melanson KJ, Saltzman E, Russell R, Roberts SB. The effects of age on postprandial thermogenesis at four graded energetic challenges: findings in young and older women. Journal of Gerontology 1998; 53B: 409-14.

54 Tuttle WW, Horvath SM, Presson LF, Daum K. Specific dynamic action in men past 60 years of age. Journal of Applied Physiology 1953; 5: 631-4. 
55 Black AE, Coward WA, Cole TJ, Prentice AM. Human energy expenditure in affluent societies: an analysis of 574 doublylabelled water measurements. European Journal of Clinical Nutrition 1996; 50: 72-92.

56 Roberts SB. Energy requirements of older individuals. European Journal of Clinical Nutrition 1996; 50(Suppl. 1): S112-8.

57 Reilly JJ, Lord A, Bunker VW, Prentice AM, Coward WA, Thomas AJ, Briggs RS. Energy balance in healthy elderly women. British Journal of Nutrition 1993; 69: 21-7.

58 Roberts SB, Young VR, Fuss P, Heyman MB, Fiatarone MA, Dallal GE, Cortiella J, Evans WJ. What are the dietary energy needs of adults? International Journal of Obesity 1992; 16 969-76.

59 Ortega RM, Andres P, Redondo MR, Zamora MJ, LopezSobaler AM, Encinas-Sotillos A. Dietary assessment of a group of elderly Spanish people. International Journal of Food Sciences and Nutrition 1995; 46(2): 137-44.

60 Roberts SB, Dallal GE. The effects of age on energy balance. American Journal of Clinical Nutrition 1998; S68: S975-9.

61 Suominen H, Heikkinen E, Parkatti T, Forsberg S, Kiiskinen A. Effects of 'lifelong' physical training on functional aging in men. Scandinavian Journal of Social Medicine 1977; 14(Suppl.): $225-40$. 